\title{
The importance of social ties in later life
}

Ella Cohn-Schwartz, Michal Levinsky, and Howard Litwin have written an important paper on the relationship between social network type and cognitive health. Their study underlines the importance of social networks in later life and yields important results in view of the increasing aging population in West European countries. Especially as cognitive decline is one of the major factors that determine whether older persons can live independently in later life.

Drawing on two waves of the Ageing, Health and Retirement in Europe (SHARE) survey, CohnSchwartz et al. (2020) offer a systematic analysis of this relationship based on five network types retrieved by means of latent class analysis. The SHARE survey offers two compelling advantages. First, the multiple waves enabled the authors to include a longitudinal dimension, regressing follow-up data on cognitive function on the network types. Second, the survey uses a "smart" approach to measuring functioning networks, asking in the first instance to name "confidants" with whom they discussed important matters. Only in the second instance were respondents asked to indicate whether these confidants are family, wider relatives, or friends. Cohn-Schwartz et al. (2020) distinguish a "friend-enhanced" network, with relatively high shares of friends, and a lower chance to be married or have children. In addition, there are "close family" (consisting mostly of spouses and children), "family poor" (consisting mostly of wider relatives), and "family rich" (spouses, children and wider relatives) networks. Finally, "multi-tie" networks consist of ties with both friends and family.

Almost $50 \%$ of the respondents belong to the "close family" network type. The two network types where friends play a meaningful role ("friendenhanced" and "multi-tie") are also characterized by a higher likelihood of performing volunteer work. Both of these networks appear to nourish cognition rather well, especially the "multi-tie", diverse network. This is because they challenge older people to continue to navigate a greater diversity of social stimuli. The lowest cognition was found in respondents with "family poor" networks. Having such a network correlates with older age, low education, and poor health. This correlation is not elaborated in detail in the paper. We can imagine that older age may imply a higher likelihood of having lost your spouse, and that older age, low education, and poor health together may lower the ability to improve the quality of contact with wider family. In hindsight, the term "family poor" may be a bit unfortunate in the sense that low cognition seems to be related mostly to the lack of having close family, rather than having only wider family.

In the remainder of this commentary, we would like to reflect on the implications of these two important findings: the role of friends and the low cognition found in "family-poor" networks.

To start with the role of friends, this finding makes for an interesting comparison with trend research on demographic change and informal care. In the Netherlands, all but the most vulnerable older people are encouraged to "age in place" in cities and local communities by mobilizing informal care networks. With growing numbers of people aging in place, also the numbers of informal carers will need to grow (De Boer et al., 2019). Yet, prognoses show a decrease in potential informal caregivers in the future (Kooiker et al., 2019). In addition, it is also predicted that more people will live further away from family (Kooiker et al., 2019) and/or will live part of their adult life outside of traditional family structures as singles, single parents, partners without children, or combined families with children from both partners (e.g. Van Duin et al., 2018).

The question then is whether, and to what extent, this informal care can be provided by friends from existing social networks. A tentative answer to this question is provided in the literature concerning lesbian, gay, bisexual, and transgender (LGBT) aging. The research by Cohn-Schwartz et al. (2020) concentrates on current networks in Western societies in which friends are seen as an "extra" next to traditional family relationships. Interestingly, the literature on networks of older LGBT people gives insight into networks that are mostly built on acquaintances and friends instead of traditional family networks, partly because LGBT persons less often have a partner and children (Hawthorne et al., 2020). Based on sets of questions in crosssectional needs assessment surveys (e.g. Croghan et al., 2014; Orel, 2014), this literature shows that friends appear to take on less intensive forms of 
informal care, although this has not systematically been investigated. The (scarce) evidence on older LGBT people with early dementia even suggests that friends may actually drop out from social networks altogether with increased cognitive decline (Fredriksen-Goldsen et al., 2018).

In sum, although friend-oriented networks are related to better cognitive health, there is a need for future research to further explore and more systematically analyze how the benefits of social networks composed partly or mainly of friends can be maintained when the care needs grow stronger, especially in situations where cognitive decline occurs. In this respect, the authors rightly mention there can also be a reverse relationship between cognitive functioning and the functioning of social networks (Cohn-Schwartz et al., 2020). This area for future research would thus take up the challenge to understand informal care provided by friends in relation to the composition of people's social networks, and the trajectories through which people become (more) engaged in informal care (Lapierre and Keating, 2013).

Another trend distinguished in the aforementioned demographic trend research in the Netherlands is that in the future, more people will be part of so-called "alternative household forms" (e.g. Jansen et al., 2008). This term points to the growing interesting in communal housing and co-housing projects, including intergenerational living arrangements. It is interesting to note that, in the Northern European context of the Netherlands, intergenerational living is seen as an "alternative household form", whereas in Southern Europe, this is a common way of living together (Cohn-Schwartz et al., 2020). We very much support the authors in their proposal to take on board household composition in future research on social networks and cognitive functioning. Aranda (2015) investigated the impact of young adults moving back in with their parents due to economic insecurity on the mental health of the parents. Interestingly, this study found the older generation in countries with a Catholic tradition showed less signs of depression, while the mental health of the older generation in countries with a Protestant tradition was not affected. Research on household composition should thus also focus on other resources that may impact social networks in households, including, for instance, health and income Girardian et al. (2020).

To support older people with "family poor" networks, the authors recommend mental health professionals to try to increase social involvement (Cohn-Schwartz et al., 2020). While we fully concur with this recommendation, we also suggest a realistic approach: for many of older persons with these networks, moving toward another network type will be extremely difficult. Therefore, we suggest to start encouraging social involvement already in "younger" cohorts of older people. At the same time, the scope of support to frail older people could be broadened by also focusing on the direct living environment. In human geography and sociology, the relationship between social-environmental embeddedness and feelings of belonging and inclusion has been widely studied, e.g. through the role of daily routines and rhythms in the neighborhood (e.g. Lager et al., 2016; Van Eck and Pijpers, 2017), and the meaning of "therapeutic landscapes" (Gesler, 1992), such as communal gardens (Milligan et al., 2004). Opportunities to meet people and use multipurpose sites foster contacts and intergenerational connections (Phillipson, 2011). Therefore, it may be argued that improving local surroundings may also influence the quality of social networks for these specific older persons. This is in line with the ideas behind the development of dementia-friendly communities (Lin and Lewis, 2015), and age-friendly cities (Van Hoof et al., 2018).

These understandings of cognitive health, social networks, and the use of the local environment would be an important addition to the finding of Cohn-Schwarz, Levinsky, and Litwin. Nevertheless, they provide highly needed scientific and policyrelevant insights into the social dimension of aging in Western Europe.

R. A. H. (Roos) Pijpers ${ }^{1}$ AND

A. P. A. (SANDRA) van BeeK ${ }^{2}$

${ }^{1}$ Associate Professor at the Institute for Management Research, Department of Geography, Planning and Environment, Radboud University Nijmegen, the Netherlands

${ }^{2}$ Senior Researcher at Nivel, the Netherlands Institute of Health Services Research, Utrecht, the Netherlands Email: r.pijpers@fm.ru.nl

\section{References}

Aranda, L. (2015). Doubling up: a gift or a shame? Intergenerational households and parental depression of older Europeans. Social Science E Medicine, 134, 12-22.

Boer de, A., Plaisier, I. and De Klerk, M. (2019). Mantelzorgers in het Vizier. The Hague: The Netherlands Institute for Social Research.

Cohn-Schwartz, E., Levinsky, M. and Litwin, H. (2020). Social network type and subsequent cognitive health among older Europeans. International Psychogeriatics, 33, 495-504.

Croghan, C. F., Moone, R. P. and Olson, A. M. (2014). Friends, family, and caregiving among midlife and older lesbian, gay, bisexual, and transgender adults. fournal of Homosexuality, 61(1), 79-102. https://doi.org/10.1080/ 00918369.2013 .835238 
Fredriksen-Goldsen, K. I., Jen, S., Bryan, A. E. B. and Goldsen, J. (2018). Cognitive impairment, Alzheimer's disease, and other dementias in the lives of lesbian, gay, bisexual and transgender (LGBT) older adults and their caregivers: needs and competencies. Fournal of Applied Gerontology, 37, 545-569.

Gesler, W. M. (1992). Therapeutic landscapes: medical issues in the light of the new cultural geography. Social Science and Medicine, 34, 735-746.

Girardian, M., Widmer, E. D., Connidis, I. A., Castrén, A. M., Gouveia, R. and Masotti, B. (2020). Ambivalence in later life familiy networks: beyond intergenerational dyads. Fournal of Marriage and Family, 80, 768-784.

Hawthorne, O., Camic, P. M. and Rimes, K. A. (2020). Understanding the Structure, Experiences and Challenges of Social Support for Older Lesbian, Gay and Bisexual People: A Systematic Review. Ageing and Society, 40, 282-305.

Jansen, H., Stavenuiter, M., Dijkhuis, A., Van Dongen, M. C. and Van Tricht, A. (2008). Gemeenschappelijk Wonen op Leeftijd. Zorgposities en Sociale Netwerken van Ouderen in Woongemeenschappen. Utrecht: Verwey-Jonker Institute.

Kooiker, S., De jonge, A., Verbeek-Oudijk, D. and De Boer, A. (2019). Toekomstverkenning mantelzorg aan ouderen in 2040. The Hague: The Netherlands Institute for Social Research.

Lager, D., Van Hoven, B. and Huigen, P. P. (2016). Rhythms, ageing and neighbourhoods. Environment and Planning A, 48, 1565-1580.

Lapierre, T. A. and Keating, N. (2013). Characteristics and contributions of non-kin carers of older people: a closer look at friends and neighbours. Ageing and Society, 33, 1442-1468.

Lin, S. Y. and Lewis, F. M. (2015). Dementia friendly, dementia capable, and dementia positive: concepts to prepare for the future. The Gerontologist, 55, 237-244.

Milligan, C., Gatrell, A. and Bingley, A. (2004). 'Cultivating health': therapeutic landscapes and older people in Northern England. Social Science E Medicine, 58, 1781-1793.

Orel, N. (2014). Investigating the Needs and Concerns of Lesbian, Gay, Bisexual, and Transgender Older Adults: The Use of Qualitative and Quantitative Methodology. Fournal of Homosexuality, 61, 53-78.

Phillipson, C. (2011). Developing age-friendly communities: New approaches to growing old in urban environments. In: J. L. Angel and R. Settersten (Eds.), Handbook of Sociology of Aging (pp 279-296). New York: Springer Nature.

Van Duin, C., Te Riele, S. and Stoeldraijer, L. (2018). Huishoudensprognose 2018-2060: Opmars Eenpersoonshuishoudens Zet Door. The Hague: Statistics Netherlands, statistical trends series.

Van Eck, D. and Pijpers, R. (2017). Encounters in place ballet: a phenomenological perspective on older people's walking routines in an Urban Park. Area, 49, 166-173.

Van Hoof, J., Kazak, J. K., Perek-Białas, J. M., Peek, S. T. M. (2018). The challenges of urban ageing: making cities age-friendly in Europe. International fournal of Environmental Research and Public Health, 15, 2473. 